\title{
Use of the oyster Crassostrea gigas embryo bioassay on water and sediment elutriate samples from the German Bight
}

\author{
J. Thain \\ Ministry of Agriculture, Fisheries and Food, Directorate of Fisheries Research, Remembrance Avenue, \\ Burnham-on-Crouch, Essex CM0 8HA, United Kingdom
}

\begin{abstract}
Oyster embryo bioassays were carried out on samples of sub-surface water, surface microlayer and sediment elutriates collected during the Bremerhaven Workshop from 9 stations along a transect from the inner German Bight to the Dogger Bank. The results gave no indication of poor water quality in the surface waters. Oyster embryo development was impaired in 2 of the 4 surface microlayer samples and in the sediment elutriate samples from the 3 inner stations.
\end{abstract}

\section{INTRODUCTION}

In 1989 proposals were put forward by ICES and IOC for a sea-going workshop to evaluate techniques that have potential for incorporation into monitoring programmes. The aims and objectives of the workshop were described in detail by Stebbing et al. (1989). One component of the workshop involved the deployment of a suite of bioassays to assess biological water quality and included the oyster embryo bioassay.

\section{METHODS}

Sample collection. All sampling and bioassays were carried out on board the RV 'Valdivia' (University of Hamburg). Nine sampling stations had been carefully selected on a previously identified contaminant gradient from the inner German Bight out to the Dogger Bank (Stebbing et al. 1989, Stebbing \& Dethlefsen 1992).

Sub-surface water samples were taken at each station at a depth of $3 \mathrm{~m}$ using a Rosette Sampler.

Sediments were also taken at each station for chemical analysis using a Reineck box corer. These samples were also used to prepare sediment elutriates which were then subjected to onboard bioassay. Sediment elutriates were prepared by mixing $200 \mathrm{ml}$ of sediment (composite sample of top $100 \mathrm{~mm}$ ) with $600 \mathrm{ml}$ of bulk water in a $1.1 \mathrm{l}$ polycarbonate bottle on an orbital shaker at $100 \mathrm{rpm}$. After $3 \mathrm{~h}$ the contents of each bottle were filtered through a Whatman GFC filter; the filtrate known as the sediment elutriate was then bioassayed. At Stns 1, 2 \& 3 less concentrated elutriates were prepared by mixing $66 \mathrm{ml}$ of sediment with $600 \mathrm{ml}$ of bulk water. The bulk water used for mixing the sediments was taken from $\operatorname{Stn} 7$ on the transect.

Surface micro-layer samples were taken at Stns 1, 4 $\& 6$ on the transect and at an additional station (designated Stn 0) east of Helgoland using a Garret screen and rotating drum sampler (Hardy \& Cleary 1992). A sub-surface bulk water sample was also taken with each surface micro-layer sample; this was taken by hand at a depth of $0.5 \mathrm{~m}$ using a glass bottle.

Oyster bioassay. The oyster embryo bioassay was carried out by the method previously described by Thain \& Watts (1984). Conditioned oysters for spawning were taken on the research ship and kept in aerated tanks of sea water until required for use. The eggs and sperm were stripped from the oysters and the developing embryos exposed to $30 \mathrm{ml}$ of test sample at $24^{\circ} \mathrm{C}$. After $24 \mathrm{~h}$ a $2 \mathrm{ml}$ subsample from each test sam- 
ple was placed under a microscope and the numbers of $\mathrm{D}$-shaped larvae counted. At least 5 replicates were used for each water column test, 4 for sediment elutriates and 3 or 4 for the surface micro-layer samples. A reference sea water of known water quality (Burnhamon-Crouch, UK, winter water) was used as a control for each bioassay.

\section{RESULTS}

The bioassay results are expressed as the mean number of normal $D$-shaped larvae to develop in the control and each of the test samples. The results are represented graphically in Figs. 1 to 4 as the mean with the $95 \%$ confidence limits. The mean proportion of Dshaped larvae in the 10 controls was $69 \%$. Statistical analysis was carried out on arcsin-transformed data using 1 -way analysis of variance using the general linear models procedure in the SAS statistical package. Dunnet's ' $t$ ' test was used to compare controls with samples from the transect to determine if differences were significant $(\mathrm{p}<0.05)$.

\section{Water column}

The results for the water column samples are shown in Fig. 1. Percentage development to Dshaped larvae at Stns 1 to 9 ranged from 65 to 75 and there were no significant differences between any of the stations along the transect.

\section{Sediment elutriate}

No D-larvae developed in the elutriate from $\operatorname{Stn} 1$. At Stns 2 \& 3 D-larval development was 10 and $57 \%$ respectively (significantly different from the control). This compares with values of 69 in the control and a range of 64 to 73 in the remaining elutriates, Stns 4 to 9 on the transect (Fig. 2). A reduction of one-third in the sediment vol- ume elutriated from Stns 1, 2 \& 3 reduced the toxic response from values of 0,10 and 57 to 56,69 and $71 \%$ D-larval development respectively.

\section{Surface micro-layer}

Four stations were successfully sampled using the Garret screen. Bulk water samples taken $0.5 \mathrm{~m}$ below the surface all gave bioassay results which were not significantly different from the controls (Fig. 3). At Stns $2 \& 6$ the surface micro-layer samples had Dlarval development values similar to the sub-surface

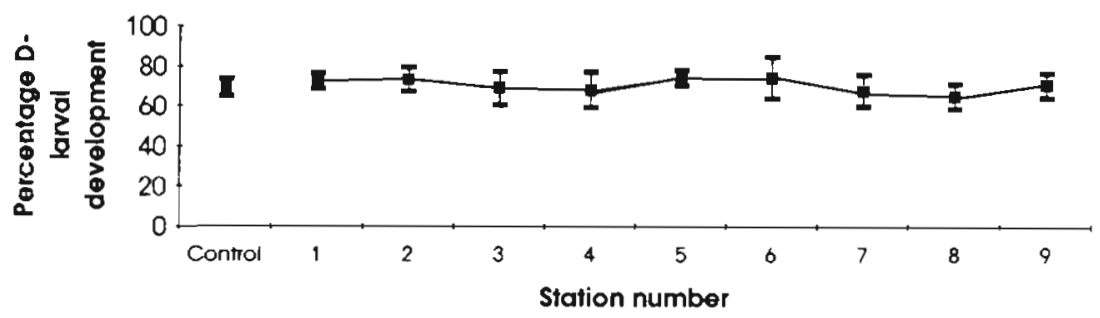

Fig. 1. Oyster embryo bioassay: water column

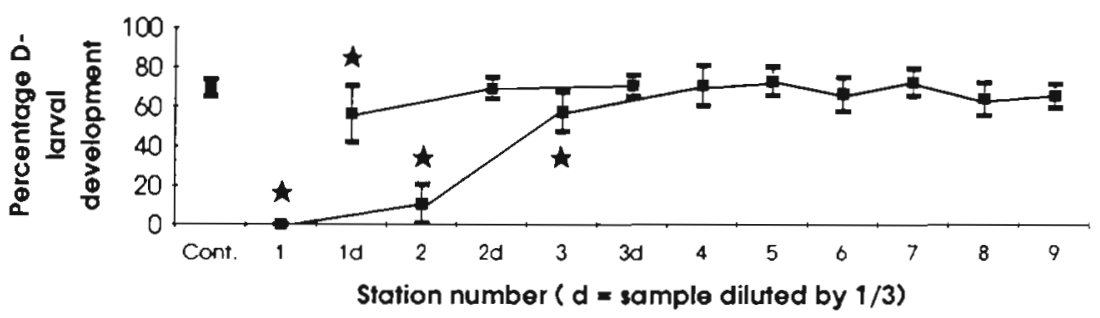

Fig. 2. Oyster embryo bioassay: sediment elutriate. ( $\star$ ) Values differ significantly from control (see text)

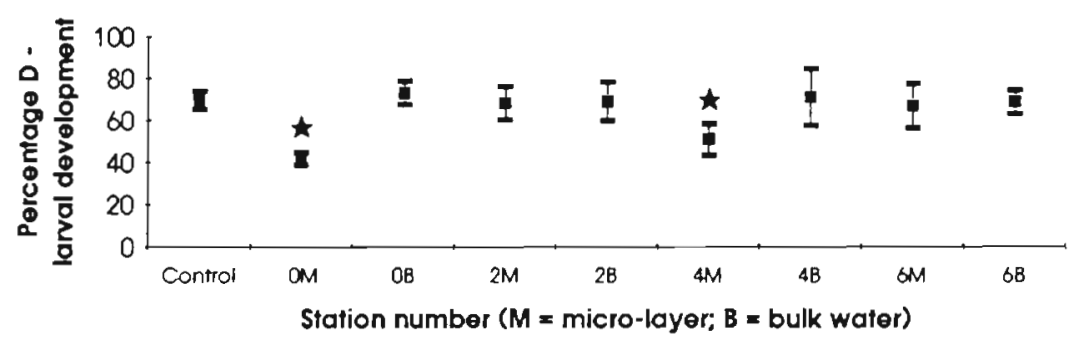

Fig. 3. Oyster embryo bioassay: Garret screen. ( Values differ significantly from control (see text)

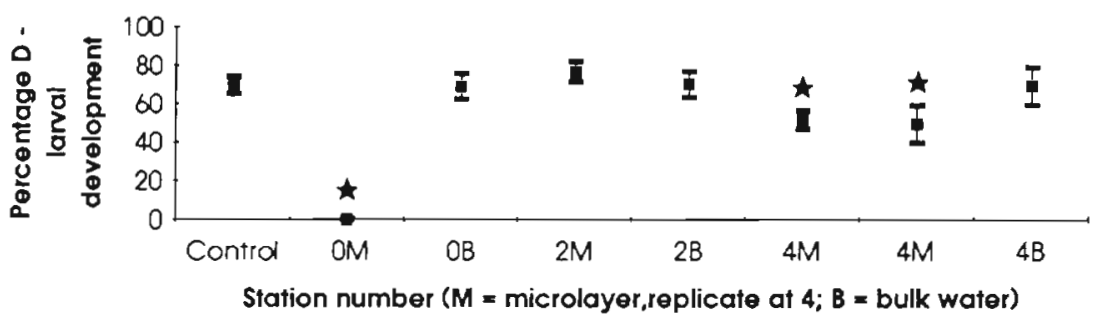

Fig. 4. Oyster embryo bioassay: Hardy sampler. ( $\star$ Values differ significantly from control (see text) 
bulk water. However, at Stn 0 (east of Helgoland) and at Stn 4, D-larval development was 44 and $49 \%$ respectively.

Results for the Hardy surface micro-layer sampler are shown in Fig. 4. In the 3 bulk water samples from Stns 0, 2 \& 4 normal D-larval development was 69,70 and $69 \%$ respectively, similar to the value of $69 \%$ recorded in the control water. In the surface micro-layer samples no impairment in D-larval development was measured in the sample from Stn 2 but at Stn 0 no larvae developed and at $\operatorname{Stn} 4$ development was significantly reduced to $49 \%$.

\section{DISCUSSION AND CONCLUSION}

The bioassay results showed that there was no measurable deleterious biological water quality in water samples taken at $0.5 \mathrm{~m}$ or greater depth along the transect. Surveys carried out by MAFF $(1990,1991)$ have also shown that surface water samples in open sea locations seldom exhibit a measurable bioassay response. Only in the vicinity of waste disposal grounds or in estuaries has the bioassay identified poor water quality (Stebbing et al. 1991).

The oyster embryo bioassay was one of the techniques selected for monitoring and surveillance of sediments for the North Sea Task Force Master Monitoring Plan (NSTF 1990). For this programme the bioassay was also performed on sediment elutriates. The same method of testing was used in this study and identified toxic sediments at Stns $1,2 \& 3$, the innermost stations in the German Bight. The bioassay clearly has some use in sediment toxicity testing but it should always be borne in mind that contaminants eluted off sediments and presented to water column organisms do not necessarily represent the exposure of these same contaminants in sediments to sedimentdwelling organisms.
The results for the surface micro-layer indicated some toxicity in samples taken at Stns 0 \& 4, irrespective of the sampling method used. Clearly, the interpretation of these results is heavily dependent on accompanying analytical chemistry (see Hardy \& Cleary 1992). However, it is questionable whether these data are of environmental relevance because they refer to an extremely thin surface layer to which neustonic organisms may not be significantly exposed

\section{LITERATURE CITED}

Hardy, J T., Cleary, J. (1992). Surface microlayer contamination and toxicity in the German Bight. Mar. Ecol. Prog. Ser. 91: $203-210$

MAFF (1990). Monitoring and surveillance of non-radioactive contaminants in the aquatic environment, 1984-1987 Aquat. Environ. Monit. Rep., MAFF Direct. Fish. Res., Lowestoft (23)

MAFF (1991). Monitoring and surveillance of non-radioactive contaminants in the aquatic environment and activities regulating the disposal of wastes at sea, 1988-1989. Aquat. Environ. Monit. Rep., MAFF Direct. Fish. Res., Lowestoft \{26\}

NSTF (1990). North Sea Task Force Monitoring Master Plan. North Sea Environment Report No 3. North Sea Task Force/Oslo and Paris Commissions/ICES, London

Stebbing, A. R. D., Cleary, J. J., Thain, J. E., Brinsley, M. D (1991). Biological and chemical indices of sewage sludge discharge at sea. In: Wrobel, L. C., Brebbia, C. A. (eds.) Water pollution, modelling, measuring and prediction Southampton Computational Mechanics and Elsevier Applied Science, p. 627-641

Stebbing, A. R. D., Dethlefsen, V. (1992). Introduction to the Bremerhaven Workshop on Biological Effects of Contamination. Mar. Ecol. Prog. Ser. 91: 1-8

Stebbing, A. R. D., Dethlefsen, V., Heip, C., Thurberg, F. (1989). ICES/IOC Workshop on the biological effects of contaminants, Bremerhaven, Federal Republic of Germany, 12-30 March 1990. International Council for the Exploration of the Sea, Copenhagen, C.M. Papers and Reports 1989/E:40,14 pp. (mimeo)

Thain, J. E., Watts, J. (1984). The use of a bioassay to measure changes in water quality associated with a bloom of Gyrodinium aureolum Hulbert. Rapp. P.-v. Réun. Cons. int. Explor. Mer 187: 103-107 